\title{
Effect of stacking fault energy on the dynamic recrystallization during hot working of FCC metals: A study using processing maps
}

\author{
Y V R K PRASAD and N RAVICHANDRAN \\ Department of Metallurgy, Indian Institute of Science, Bangalore 560 012, India \\ MS received 12 March 1991
}

\begin{abstract}
The influence of stacking fault energy (SFE) on the mechanism of dynamic recrystallization (DRX) during hot deformation of FCC metals is examined in the light of results from the power dissipation maps. The DRX domain for high SFE metals like Al and $\mathrm{Ni}$ occurred at homologous temperature below 0.7 and strain rates of $0.001 \mathrm{~s}^{-1}$ while for low SFE metals like $\mathrm{Cu}$ and $\mathrm{Pb}$ the corresponding values are higher than 0.8 and $100 \mathrm{~s}^{-1}$. The peak efficiencies of power dissipation are $50 \%$ and below $40 \%$ respectively. A simple model which considers the rate of interface formation (nucleation) involving dislocation generation and simultaneous recovery and the rate of interface migration (growth) occurring with the reduction in interface energy as the driving force, has been proposed to account for the effect of SFE on DRX. The calculations reveal that in high SFE metals, interface migration controls DRX while the interface formation is the controlling factor in low SFE metals. In the latter case, the occurrence of flow softening and oscillations could be accounted for by this model.
\end{abstract}

Keywords. Dynamic recrystallization; stacking fault energy; power dissipation maps.

\section{Introduction}

The mechanism of-dynamic recrystallization (DRX) has been extensively studied during hot deformation in several FCC metals and has recently been reviewed (Sakai and Jonas 1984; Roberts 1984; McQueen et al 1990). These studies generally indicate that high stacking fault energy (SFE) metals like Al do not undergo DRX while low SFE metals like $\mathrm{Cu}$ exhibit stress-strain curves with flow softening or oscillations which are considered as indications of DRX. In low SFE metals, a temperature and strain rate-dependent critical strain is identified at which the flow stress reaches a maximum value before attaining a steady state under constant strain rate conditions. The mechanism of DRX is evaluated using kinetic approaches and a characteristic range of Zener-Holloman parameter is indicated for DRX (Sakui et al 1977). The apparent activation energy for DRX is much higher than that for self-diffusion in many cases (Sellars and McG. Tegart 1969). The mechanism of DRX was thought to involve nucleation at subgrains produced by deformation and simultaneous recovery and followed by migration (growth) of the grain boundaries driven by the stored energy of deformation. Microstructural observations showing fine-grained nuclei at prior grain boundaries are taken as confirmations of DRX (Ueki et al 1987).

In recent years, however, the hot deformation characteristics are modelled using the dynamic materials model (DMM) (Prasad et al 1984), the outcome being the power dissipation map representing power dissipation by the workpiece through microstructural changes as a function of temperature and strain rate. This map clearly reveals a domain of dynamic recrystallization in which the workability reaches its maximum value and the grain size variations with temperature are 
similar (sigmoidal) to those in static recrystallization. The DMM approach has shown that the present understanding of DRX is inadequate for the following reasons:

(i) DRX is found to occur even in high SFE metals like Al and its characteristics are purity-dependent (Ravichandran and Prasad 1991).

(ii) The microstructural observations reported in several cases supposedly representing DRX are actually done away from the DRX domain (Blaz et al 1983; Sakai et al 1984; Ueki et al 1987).

(iii) As the system is dynamic, the rate of nucleation vs rate of migration (growth) should be considered for a given boundary condition (e.g. constant true strain rate) in order to explain the shape of stress-strain curves. The recent model suggested by Derby and Ashby (1987) considers this aspect of DRX.

This paper is a preliminary report of the new results obtained on the characteristics of DRX in FCC metals studied using power dissipation maps. These maps represent the efficiency of power dissipation of the workpiece through microstructural changes as compared with an ideal linear dissipator in a wide range of temperature and strain rate. The map exhibits several domains which may be interpreted in terms of microstructural processes like dynamic recovery, DRX, void formation and wedge cracking on lines similar to Raj maps (Raj 1981). The power dissipation maps for several $\mathrm{FCC}$ metals like $\mathrm{Al}, \mathrm{Ni}, \gamma-\mathrm{Fe}, \mathrm{Cu}$ and $\mathrm{Pb}$ have been examined and the DRX domain identified for further analysis of the effect of SFE on the DRX characteristics. A simple model of DRX has been proposed on the basis of these observations.

\section{Experimental results on processing maps}

The temperatures and strain rates corresponding to the peak efficiency of power dissipation maps of $\mathrm{FCC}$ metals $\mathrm{Al}, \mathrm{Ni}, \gamma-\mathrm{Fe}, \mathrm{Cu}$ and $\mathrm{Pb}$ are given in table 1 . The peak efficiency values and general remarks on the shape of stress-strain curves and other relevant observations are also included in this table. The effect of purity on the DRX characteristics of $\mathrm{Al}$ and $\mathrm{Cu}$ are based on extensive experimental results which will be published in detail elsewhere. The dependence of DRX parameters on SFE is shown in figure 1 as a function of $(\gamma / G b)$ where $G$ is the shear modulus and $b$ the Burgers vector. In general, the strain rate and temperature for DRX of high SFE metals (Al and $\mathrm{Ni}$ ) are lower (strain rates of $\leq 10^{-3}$ and $T / T_{m} \leq 0.75$ ) than those for low SFE metals $(\mathrm{Cu}$ and $\mathrm{Pb})$ (strain rates $\geq 100$ and $\left.T / T_{m} \geq 0 \cdot 8\right)$. $\gamma$-iron falls in the intermediate range. The efficiency of power dissipation is higher for high SFE metals $(\approx 50 \%)$ than for low SFE metals $(\approx 40 \%)$.

\section{Model for DRX}

Earlier studies (Sakai and Jonas 1984; Roberts 1984; McQueen et al 1990) have considered DRX as a kinetic process and proposed a model on the basis of microstructural observations. It is suggested that DRX occurs by a nucleation and growth process involving subgrain formation and grain boundary migration respectively. Three important results have been drawn from these studies.

(i) High SFE metals like Al undergo only dynamic recovery and do not exhibit DRX. 
Table 1. Summary of results on DRX from power dissipation maps on FCC metals.

\begin{tabular}{|c|c|c|c|c|c|}
\hline Metal & $\begin{array}{c}\text { DRX } \\
\text { Temp }\left({ }^{\circ} \mathrm{C}\right)\end{array}$ & $T / T_{m}$ & $\begin{array}{c}\text { DRX } \\
\left(\dot{\varepsilon}, s^{-1}\right)\end{array}$ & $\begin{array}{l}\text { Peak } \\
(\eta, \%)\end{array}$ & Remarks \\
\hline $\begin{array}{l}\mathrm{Al} \\
99.99 \%\end{array}$ & 450 & 0.78 & 0.001 & 58 & $\begin{array}{l}\text { Steady-state } \sigma-\dot{\varepsilon} \text { curves; DRX } \\
\text { temperature is higher for lower } \\
\text { purity; DRX } \dot{\varepsilon} \text { unaffected }\end{array}$ \\
\hline $\begin{array}{l}\mathrm{Ni} \\
99 \cdot 5 \%\end{array}$ & 850 & $0-65$ & 0.0003 & 48 & $\begin{array}{l}\text { Steady-state } \sigma-\varepsilon \text { curves; For } \\
T / T_{m}=0.86 \text { wedge cracking } \\
\text { domain occurs with higher effici- } \\
\text { ency, }(\approx 60 \%)\end{array}$ \\
\hline $\begin{array}{l}\gamma \text {-Fe } \\
\text { ARMCO }\end{array}$ & 1150 & 0.8 & 0.1 & 40 & $\begin{array}{l}\text { Flow softening and oscillations; } \\
\text { Map for } 0 \cdot 16 \% \mathrm{C} \text { steel* is similar }\end{array}$ \\
\hline $\begin{array}{l}\text { OFHC } \\
\mathrm{Cu} \\
15 \mathrm{ppm} \mathrm{O}\end{array}$ & 850 & 0.83 & 100 & 36 & $\begin{array}{l}\text { Flow softening and oscillations; } \\
\text { DRX } \dot{\varepsilon} \text { is lower for higher } \\
\text { oxygen content; DRX temperature } \\
\text { unaffected }\end{array}$ \\
\hline $\mathrm{Pb}$ & 235 & 0.85 & 300 & 41 & $\begin{array}{l}\text { Flow softening; Map** revealed } \\
\text { a superplasticity domain at } \\
T / T_{m}=0.91 \text { and } \dot{\varepsilon}=0.4 \mathrm{~s}^{-1} \text {, peak } \\
\text { efficiency is } 74 \%\end{array}$ \\
\hline
\end{tabular}

* Developed on the basis of extrusion data for Hughes et al (1974).

** Developed on the basis of hot compression data of Baily and Singer (1963-64).

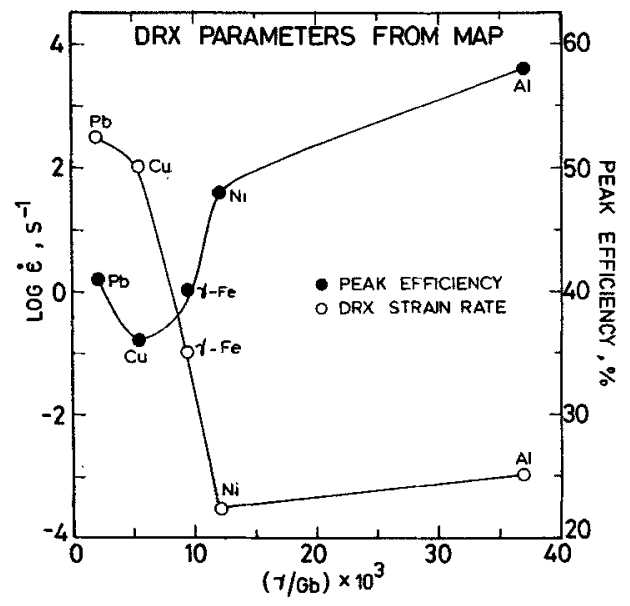

Figure 1. DRX strain rates and peak efficiency of power dissipation in FCC metals.

(ii) Grain boundary migration occurs as a softening process and the driving force for this is the stored energy of individual dislocations generated during deformation. (iii) Oscillations in the stress-strain curves occur when the grain boundary migration comes to a halt and new nuclei form in the unrecrystallized regions.

The above mechanism, however, needs careful analysis for the following reasons: (a) As in the case of static recrystallization, the occurrence of dynamic recovery is a prerequisite to DRX. The higher rate of dynamic recovery (nucleation) should promote DRX process in high SFE metals. 
(b) The driving force for grain boundary migration is the reduction in the total energy of interfaces and not the stored energy of individual dislocations unlike in SRX, since the material essentially acts as a dissipator of power during deformation at elevated temperatures. It is also important to note that in high temperature deformation dislocation generation and recovery processes occur simultaneously leading to the formation of interfaces or subgrains.

(c) Oscillations in the stress-strain curves occur at higher temperatures and lower strain rates and both these conditions actually promote grain boundary migration. Further in a dynamic situation (strain being applied at a given rate) it is unlikely that any process halts, although the rate of occurrence could vary with temperature and strain rate.

In view of the above discrepancies, a simple model is proposed for DRX where the rate of nucleation vs rate of growth are considered as the key factors that determine the nature of DRX process.

It will be beneficial first to consider the differences between static and dynamic recrystallization processes. Static recrystallization occurs by a nucleation and growth process in order to release a certain constant amount of energy input into the material by cold work. Nucleation occurs by the formation of subgrains following annihilation (recovery) and rearrangement of dislocations while growth occurs by the migration of grain boundaries formed when some of the nuclei attain large angle configurations either by subgrain coalescence or dislocation absorption. The driving force for the growth process is the stored energy and the grain boundary migration continues until the stored energy is exhausted. In dynamic recrystallization, however, there is certain energy input per second depending upon the strain rate and temperature and certain rate of energy dissipation due to softening processes and the behaviour represents a dynamic balance between the rates of nucleation and growth under given boundary conditions. Thus, dynamic recrystallization may consist of two competing processes: formation of interfaces (nucleation) and migration of interfaces (growth). An interface may be defined as a boundary formed as a result of dislocation generation, recovery and rearrangement, and will migrate (nucleus) when it attains a configuration of a large angle boundary. As the material under hot working conditions acts essentially as a dissipator of power (no significant energy storage), the driving force for migration of interfaces is dislocations forming subgrains. Under constant true strain rate conditions, the rate of formation of interfaces will compete with the rate of migration in such a way as to maintain constant the strain rate with strain and the relative values of these two rates will decide the shape of the stress-strain curves. For example, if these two rates lead to comparable changes in the interface area, steady-state curves result. If the rate of interface formation is slower than the rate of migration, certain strain will have to elapse before the critical configuration of the migration of the interface is achieved and at the critical strain a large number of interfaces migrate leading to flow softening. The situation is similar to the spring-dash pot model under damped free vibration conditions. Damped oscillations may result if the rate of formation of interfaces is further lowered e.g. by lowering the applied strain rate.

On the basis of the above model, the influence of SFE on the characteristics of DRX is examined in detail below. The rate of interface formation $R_{F}$ depends on the rate of generation of recovered dislocations:

$$
R_{F}=\beta \cdot \dot{\varepsilon} \cdot P_{R} /(b l)
$$


where $\beta$ is the constant, $\dot{\varepsilon}$ the strain rate, $l$ the dislocation link length and $P_{R}$ the probability of recovery of dislocations. For mechanical recovery involving cross slip of screw dislocations (Friedel 1964)

$$
P_{R}=\exp \left(-\alpha G b^{2} d(\ln d / b)^{1 / 2} /(k T)\right),
$$

where $\alpha$ is the constant (0.06), $G$ the shear modulus, $d$ the stacking fault width, $k$ the Boltzman constant and $T$ the temperature. For thermal recovery involving climb of edge dislocations,

$$
P_{R}=\exp \left(-Q_{\mathrm{SD}} / \mathrm{RT}\right),
$$

where $Q_{\mathrm{SD}}$ is the activation energy for self-diffusion and $R$ the gas constant. At the temperature and strain rate of DRX, the calculated values of $R_{F}$ corresponding to mechanical recovery and thermal recovery in FCC metals are given in table 2 and plotted against $(\gamma / G b)$ in figure 2 .

From figure 2 it is seen that recovery by cross-slip is faster for high SFE metals $\mathrm{Al}$ and $\mathrm{Ni}$ while recovery by climb is faster for low SFE metals $\mathrm{Cu}$ and $\mathrm{Pb}$. In $\gamma-\mathrm{Fe}$, faster recovery occurs by cross-slip than by climb.

The mobility $M$ of grain boundaries is given by (Smith et al 1980)

$$
M=D \Gamma / k T b,
$$

where $D=D_{0} \exp -\left(Q_{\mathrm{SD}} / \mathrm{RT}\right)$ is the diffusion coefficient and $\Gamma$ is the grain boundary energy. The rate of annihilation of recovered groups of dislocations (subgrains) caused by the migration of interfaces, $R_{M}$, may be assumed to be proportional to $M$ :

$$
R_{M}=c . M \text {, }
$$

where $c$ the constant is assumed to be about $10^{-6} \mathrm{~m}^{-1}$. The calculated values of $R_{M}$ for various FCC metals are shown in table 2 and plotted as a function of $(\gamma / G b)$ in figure 3. The controlling $R_{F}$ values are also shown in figure 3 for comparison. It is seen that for high SFE metals $\mathrm{Al}$ and $\mathrm{Ni}$, the $R_{M}$ values are lower than $R_{F}$ and

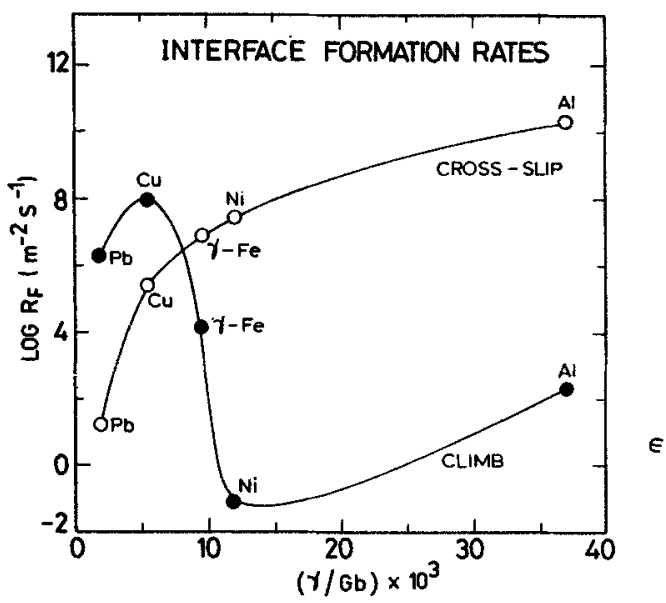

Figure 2. Rates of interface formation by cross-slip (equations (1) and (2)) and climb (equations (1) and (3)) in FCC metals. 
Table 2. Calculated values of rate of interface formation occurring :by recovery due to cross-slip and climb for FCC metals.

\begin{tabular}{|c|c|c|c|c|c|c|c|c|}
\hline Metal & $\begin{array}{c}\gamma \\
S F E^{*} \\
\left(\mathrm{~mJ} / \mathrm{m}^{2}\right)\end{array}$ & $\begin{array}{c}b \\
(\AA)\end{array}$ & $\begin{array}{l}\text { SF width } \\
\left(\mathrm{d} \text { in } \mathrm{b}^{*}\right)\end{array}$ & $\begin{array}{l}G \text { at } \\
\text { DRX } \\
\text { temp. } \\
\text { (GPa) }\end{array}$ & $\begin{array}{l}\gamma / G b \\
\times 10^{3}\end{array}$ & $\underset{(\mathrm{kJ} / \mathrm{mol})}{\mathcal{Q}_{\mathrm{SD}}}$ & $\begin{array}{c}R_{\boldsymbol{F}} \\
\text { cross } \\
\text { slip } \\
\left(\mathrm{m}^{-2} \mathrm{~s}^{-1}\right)\end{array}$ & $\begin{array}{c}R_{F} \\
\operatorname{climb} \\
\left(\mathbf{m}^{-2} s^{-1}\right)\end{array}$ \\
\hline Al & 200 & $2 \cdot 86$ & 1.5 & 19.0 & $37 \cdot 0$ & 142 & $2.0 \times 10^{10}$ & $2 \times 10^{2}$ \\
\hline $\mathrm{Ni}$ & 165 & 2.50 & 30 & 53.3 & 12.0 & 284 & $2.5 \times 10^{7}$ & $9 \times 10^{-2}$ \\
\hline$\gamma-\mathrm{Fe}$ & $78^{\dagger}$ & $2 \cdot 58$ & 7.0 & $32 \cdot 3$ & $9 \cdot 4$ & 270 & $8.4 \times 10^{6}$ & $1.6 \times 10^{4}$ \\
\hline $\mathrm{Cu}$ & 40 & 2.56 & 100 & $28 \cdot 2$ & $5 \cdot 5$ & 197 & $2.4 \times 10^{5}$ & $8.9 \times 10^{7}$ \\
\hline $\mathrm{Pb}$ & $6^{+}$ & 3.49 & 12.0 & $5 \cdot 4$ & 2.0 & 109 & 15 & $1.8 \times 10^{6}$ \\
\hline
\end{tabular}

*Friedel (1964).

tassumed on the basis of mechanical behaviour.

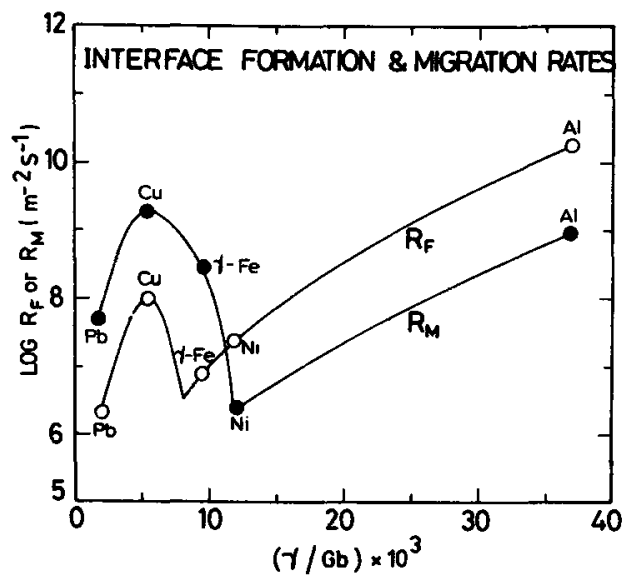

Figure 3. Comparison of interface formation rate (equations (1)-(3)) with migration rate (equations (4) and (5)) in FCC metals.

hence DRX is grain-boundary-migration-controlled. Hence impurities will have a significant effect on DRX temperature since the grain boundary energy is sensitive to the impurity content. Also since the DRX process is diffusion-controlled (4) and (5), slower strain rates are preferred. On the other hand for low SFE metals like $\mathrm{Cu}$ and $\mathrm{Pb}, R_{F}$ values are lower than $R_{M}$ values and hence $\mathrm{DRX}$ is controlled by the formation of interfaces. Since the rate of recovery by climb is slower, the strain rates will have to be higher to produce enough number of recovered dislocations to form the critical configuration of the interface for migration. Hence DRX occurs at high strain rates. Also since climb involves diffusion, higher $T / T_{m}$ values are required for DRX of low SFE metals. Although interface formation in $\gamma$-Fe occurs by cross-slip, $R_{F}$ values are lower than $R_{M}$ and hence it behaves like a low SFE metal. In all these casses where $R_{F}<R_{M}$, flow softening is observed and when the strain rates are further lowered oscillations in the stress-strain curves appear since $R_{F} \ll R_{M}$. In the earlier DRX models (Sakai and Jonas 1984; Roberts 1984; McQueen et al 1990), the occurrence of oscillations is interpreted in terms of the halting of grain boundary migration and the forming of new nuclei in the unrecrystallized regions. 
Table 3. Calculated values of interface formation and migration rates in FCC metals.

\begin{tabular}{llcccc}
\hline Metal & $\begin{array}{c}\text { Recovery } \\
\text { process }\end{array}$ & $\begin{array}{c}\text { D at DRX } \\
\text { temp }\left(\mathrm{m}^{2} / \mathrm{sec}\right)\end{array}$ & $\begin{array}{c}\Gamma \\
\left(\mathrm{mJ} / \mathrm{m}^{2}\right)\end{array}$ & $\begin{array}{c}\dot{R}_{F} \\
\left(\mathrm{~m}^{-2} \mathrm{~s}^{-1}\right)\end{array}$ & $\begin{array}{c}R_{M} \\
\left(\mathrm{~m}^{-2} \mathrm{~s}^{-1}\right)\end{array}$ \\
\hline $\mathrm{Al}$ & Cross-slip & $9.4 \times 10^{-15}$ & 324 & $2 \times 10^{10}$ & $1.1 \times 10^{9}$ \\
$\mathrm{Ni}$ & Cross-slip & $1.2 \times 10^{-17}$ & 866 & $2.5 \times 10^{7}$ & $2.6 \times 10^{6}$ \\
$\gamma-\mathrm{Fe}$ & Cross-slip & $2.2 \times 10^{-15}$ & 756 & $8.4 \times 10^{6}$ & $3.2 \times 10^{8}$ \\
$\mathrm{Cu}$ & Climb & $1.4 \times 10^{-14}$ & 625 & $8.9 \times 10^{7}$ & $2.2 \times 10^{9}$ \\
$\mathrm{~Pb}$ & Climb & $8.7 \times 10^{-16}$ & 200 & $1.8 \times 10^{6}$ & $5.3 \times 10^{7}$ \\
\hline
\end{tabular}

However, in view of the slow strain rates at which the oscillations occur, the high temperatures and the driving force due to the presence of subgrains, it is unlikely that the grain boundary migration comes to a halt. On the other hand the present model predicts oscillations when the migration rates far exceed the formation rates.

In low SFE metals like $\mathrm{Cu}$, the presence of interstitial impurities and fine particles will enhance the rate of generation of dislocation and hence the interface formation rates. This effect will result in a lowering of strain rates at which DRX occurs. Further the efficiency of power dissipation in DRX of low SFE metal will be lower since the formation of interfaces is less efficient compared to migration.

\section{Conclusions}

Studies of dynamic recrystallization process in hot working of $\mathrm{FCC}$ metals $\mathrm{Al}, \mathrm{Ni}$, $\gamma-\mathrm{Fe}, \mathrm{Cu}$ and $\mathrm{Pb}$ using the power dissipation maps have revealed the following features:

(i) DRX in high SFE metals $\mathrm{Al}$ and Ni occurs at low strain rates $\left(\dot{\varepsilon}<10^{-3} \mathrm{~s}^{-1}\right)$ and lower temperatures $\left(T / T_{m}<0.75\right)$ while in low SFE metals $\mathrm{Cu}$ and $\mathrm{Pb}$ it requires higher strain rates $\left(\dot{\varepsilon}>100 \mathrm{~s}^{-1}\right)$ and higher temperatures $\left(T / T_{m}>0.8\right)$.

(ii) The process of dynamic recovery which is a pre-requisite for DRX, occurs by mechanical recovery (cross-slip) in high SFE metals and by thermal recovery (climb) in low SFE metals.

(iii) DRX is controlled by the process of interface migration in the case of high SFE metals while the interface formation is the controlling step in low SFE metals. (iv) DRX in high SFE metals is more efficient $(\approx 50 \%)$ in dissipating powe than in low SFE metals $(\approx 40 \%)$.

\section{References}

Baily J A and Singer A R E 1963-64 J. Inst. Met. 92404

Blaz L, Sakai T and Jonas J J 1983 Metal Sci. 21619

Derby B and Ashby M F 1987 Scr. Metall. 21879

Friedel J 1964 in Dislocations (Oxford: Pergamon Press) 158, 164

Hughes K E, Nair K D and Sellars C M 1974 Met. Technol. 1161

McQueen H J, Evangelista E and Ryan N D 1990 in Proceedings of Recrystallization, 1990 (ed.) T Chandra (Australia: TMS-AIME Pennsylvania) 89

Prasad Y V R K, Gegel H L, Doraivelu S M, Malas J C, Morgan J T, Lark K A and Barker D R 1984 Metall. Trans. A15 1883

Raj R 1981 Metall. Trans. A12 1089 
Ravichandran N and Prasad Y V R K 1991 Metall. Trans. (To be published)

Roberts W 1984 in Deformation, processing and structures, (ed.) G Krauss (Metals Park, Ohio: Am. Soc. Mater.) 109

Sakai T and Jonas J J 1984 Acta Metall. 32189

Sakui S, Sakai T and Takeishi T 1977 Trans. Iron Steel Inst. Jpn 17718

Sellars C M and McG. Tegart T G 1969 Met. Rev. 141

Smith D A, Rae C M F and Grovenor C R M 1980 in Grain boundary structurè and kinetics (ed.) R W Balluffi (Metals Park, Ohio: Am. Soc. Mater.) 347

Ueki M, Horie S and Nakamura T 1987 Mater. Sci. Technol. 3329 